Louisiana State University

LSU Digital Commons

1969

\title{
Visual Discrimination Performance in Rats Following Nucleus Posterior Thalami and Di-Mesencephalic Juncture Damage.
}

\author{
Billy Michael Thorne \\ Louisiana State University and Agricultural \& Mechanical College
}

Follow this and additional works at: https://digitalcommons.Isu.edu/gradschool_disstheses

\section{Recommended Citation}

Thorne, Billy Michael, "Visual Discrimination Performance in Rats Following Nucleus Posterior Thalami and Di-Mesencephalic Juncture Damage." (1969). LSU Historical Dissertations and Theses. 1699. https://digitalcommons.Isu.edu/gradschool_disstheses/1699 
This dissertation has been

microfilmed exactly as received

70 9099

THORNE, Billy Michael, 1942-

VISUAL DISCRIMINATION PERFORMANCE IN RATS

FOLLOWING NUCLEUS POSTERIOR THALAMI AND

DI-MESENCEPHALIC JUNCTURE DAMAGE.

The Louisiana State University and Agricultural and

Mechanical College, Ph.D., 1969

Psychology, experimental

University Microfilms, Inc., Ann Arbor, Michigan 
VISUAL DISCRIMINATION PERFORMANCE IN RATS FOLLOWING NUCLEUS POSTERIOR THALAMI AND DI-MESENCEPHALIC JUNCTURE DAMAGE

A Dissertation

\section{Submitted to the Graduate Faculty of the Louisiana State University and Agricultural and Mechanical College in partial fulfillment of the requirements for the degree of Doctor of Philosophy}

in

The Department of Psychology

by

Billy Michael Thorne

B.A., Louisiana State University, 1964

M.A., Louisiana State University, 1967

August, 1969 
I would like to express my gratitude to Dr. Robert Thompson, committee chairman and major professor, for his support, guidance, and patience throughout the entire research project. I would also like to thank the other members of my committee, Drs. Billy M. Seay, Donald R. Hoffeld, A. Clinton Pereboom, and George C. Kent. Also appreciated were the suggestions and criticisms from my colleagues at the Brain Research Laboratory. I would like to thank Mrs. Mary Mevers for her aid in preparing the final copy of the manuscript. My wife also deserves a special word of thanks for her help in preparing innumerable drafts and for her support during a trying period in our lives.

The research was in part supported by Grant MH-08377, National Institute of Menta 1 Health, USPHS, and in part by a National Aeronautics and Space Administration Traineeship held by the author. 
TABLE OF CONTENTS

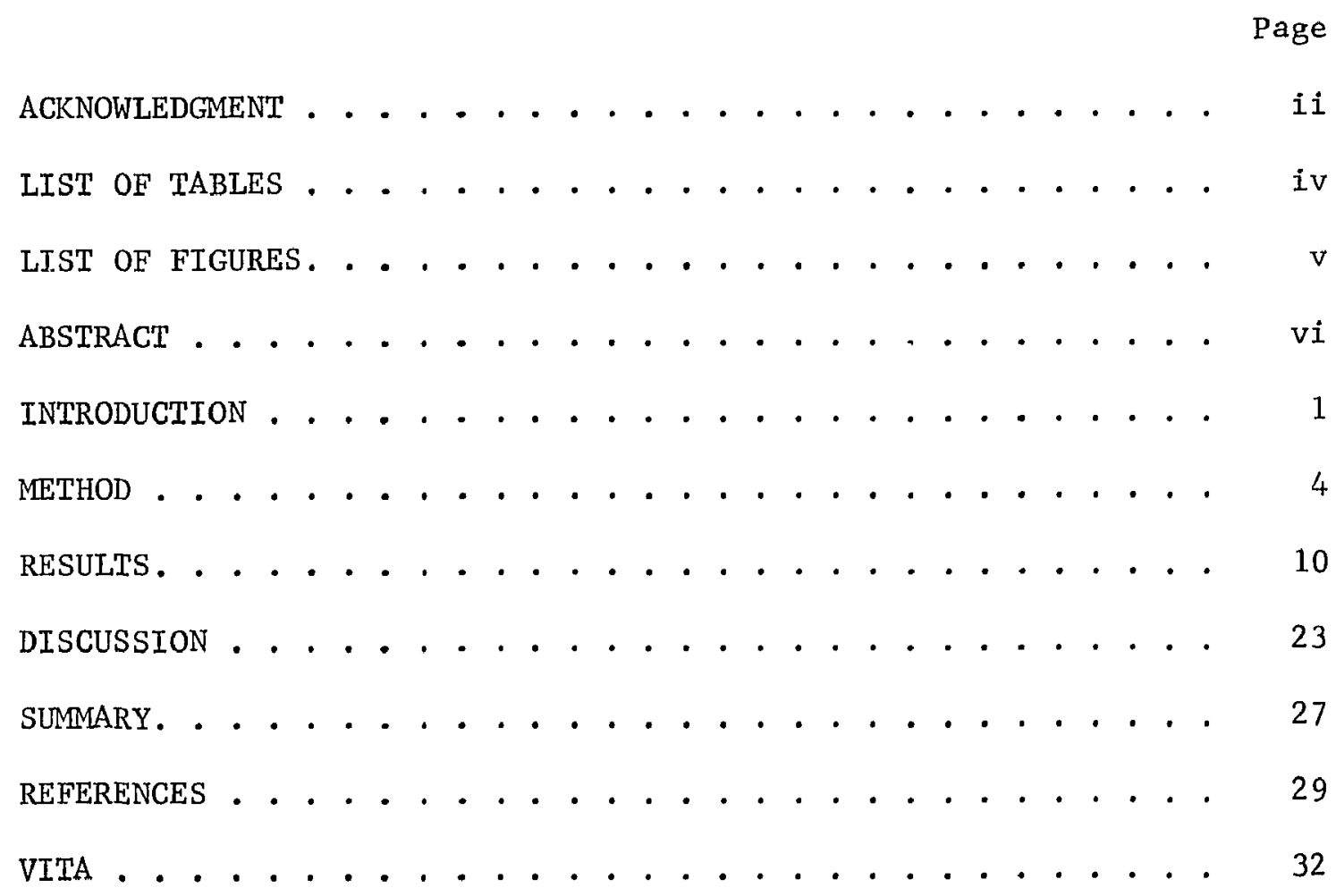




\section{LIST OF TABLES}

Table

Page

1. Preoperative Learning Performance of Groups C,

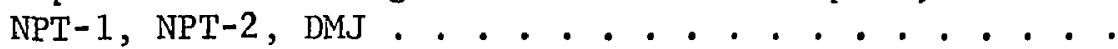

2. Mean Retention Scores for Groups C, NPT-1, NPT-2, DMJ .

3. Number of Ss in Each Group Attaining Criterion on Size Discrimination Threshold Tasks . . . . . . .

4. Spearman Rho Correlation Coefficients Between Retention Scores and Size Threshold Performance Computed on the Operate Ss. . . . . . . . . . . .

5. Spearman Rho Correlation Coefficients Between Retention Scores and \% Damage to Thalamic Areas for Ss in Combined NPT Groups . . . . . . . . . . 


\section{LIST OF FIGURES}

$\begin{array}{ll}\text { Figure } & \text { Page }\end{array}$

1. Unstained Sections from Two NPT Ss Having Retention Loss on Both Problems . . . . . . . . . . . . . 14

2. Unstained Sections from Two Ss Having Approximately Equivalent Damage to NPT. . . . . . . . . . 15

3. Five Fronta1 Levels Derived from the Massopust (1961) Atlas................ 20

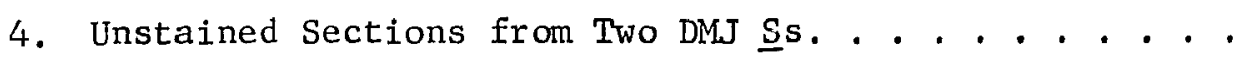




\begin{abstract}
Following training on both a size discrimination and a pattern discrimination problem, adult albino rats were given either 1-stage or 2-stage nucleus posterior lesions, 1-stage lesions to the dimesencephalic juncture, or no lesions. Postoperative testing revealed that (a) brain-damaged $\underline{S} s$ performed more poorly than normal controls in relearning the two visual habits, (b) 2 -stage nucleus posterior lesioned $\underline{S} s$ were not significantly different from 1-stage nucleus posterior lesioned animals, and (c) brain-damaged $\underline{S} s$ did not differ significantly from normals with respect to performance on a size threshold task. This pattern of results suggests that neither diaschitic effects nor loss of visual acuity can adequately account for visual discrimination retention deficits induced by nucleus posterior lesions. The data also provide further evidence for the existence of a pathway through the di-mesencephalic juncture which is functionally significant in visual discrimination performance.
\end{abstract}




\section{INTRODUCTION}

Within the last decade, several articles have appeared in the neuropsychological literature which suggest that the region of the pretecto-diencephalon, and in particular the nucleus posterior thalami (NPT), is critical for retention of visual discrimination problems in the albino rat (Hore1, 1968; McNew and Thompson, 1966; Thompson, 1963; Thompson, Lesse, and Rich, 1963; Thompson, Lukaszewska, Schweigerdt, and McNew, 1967; Thompson and Massopust, 1960; Thompson and Rich, 1961; Thompson and Rich, 1963; Thompson, Rich, and Langer, 1964). Earlier studies by Ghiselli and Brown (1938), Lashley (1935), Layman (1936), and Papez and Freeman (1930) also suggested the importance of the pretectal diencephalon for mediation of visual discrimination performance. One interpretation of the retention deficits following NPT damage was made by Thompson (1965) who suggested that the NPT functions as a sensory relay station between the visual cortex and the ventral midbrain in a "centrencephalic-type" visual memory system.

If the NPT serves as a sensory relay station in a pathway extending from visual cortex to ventral midbrain, then lesions of this structure might be expected to produce not only amnesia for previously learned problems but sensory deficits as well. Although there is little evidence for occipitofugal fibers entering the NPT directly (Goodman and Hore1, 1966; Knook, 1966, p. 331), Hore1 (1968) reported that the ventral nucleus of the lateral geniculate body both receives occipitofugal fibers and projects to the NPT. Thus, while an anatomical basis 
exists for a loss in visual acuity following damage to the NPT, there has been no systematic attempt to relate amnestic effects of NPT lesions with corresponding sensory defects.

Another possible explanation for the loss of retention following NPT lesions is that such lesions may have diaschitic effects. This interpretation is based upon the fact that diverse ascending and descending fiber systems course through or originate in the pretectodiencephalon (Knook, 1966, pp. 311-347; Krieg, 1947; Papez and Freeman, 1930). Thus, interruption of these fiber tracts coincident with NPT lesions might produce disfunctioning of cortical and/or brainstem mechanisms unrelated to the channeling of visual input from the occipital cortex to the ventral midbrain. The possibility of a diaschitic effect remains as long as NPT lesions are made in 1-stage operations (simu1taneous, bilatera1). Since there is an indication that 2-stage lesions (successive, bilateral) produce less disruptive (diaschitic) effects on behavior than 1-stage lesions (Adametz, 1959; Ades and Raab, 1949; Stewart and Ades, 1951), a study comparing the effects of 1-stage versus 2-stage lesions of the NPT on retention would provide a reasonable test of the diaschitic hypothesis.

Although the anatomical connection between the NPT and the ventral midbrain is wel1 established (Knook, 1966, p. 331; Krieg, 1947; Papez and Freeman, 1930), the functional significance of this pathway remains obscure. The anatomical studies cited are in general agreement concerning the trajectory of the descending fibers through the dimesencephalic zone. Knook, for example, described the path taken by 
degenerating fibers from the NPT as follows: a ". . heavy degenerated bundle arches somewhat ventromedially to the dorsal surface of the medial lemniscus... [and] partly traverses the nucleus ruber to which an astonishing large number of degenerated fibres are distributed . . "(p. 331). If this tract is essential for the performance of visually-guided behavior as suggested by an earlier study (Thompson, et al., 1964), then lesions of the di-mesencephalic juncture (DMJ) through which this tract penetrates would be expected to abolish previously learned visual discrimination habits.

In the current study, rats previously overtrained on two separate visual discrimination problems received either 1-stage or 2-stage bilateral NPT lesions, 1-stage bilateral DMJ lesions, or served as nonoperated controls. After a suitable recovery period, a11 $\underline{S}$ s were tested for retention of the originally learned problems, and almost a11 of the animals were subsequently trained on a size discrimination threshold test. 
METHOD

\section{Subjects}

The Ss were 34 adult male albino rats of the Wistar strain. Following discrimination training, 20 animals, 10 per group, received either 1-stage or 2-stage lesions to the region of the NPT (Groups NPT-1 and NPT-2, respective1y), 7 Ss received bilatera1 1-stage lesions to the DMJ (Group DMJ) and 7 Ss served as normal controls (Group C).

\section{Surgery and histology}

Al1 surgical procedures were performed under deep chloral hydrate anesthesia. The rat atlas of Massopust (1961) was used to determine the coordinates to be employed in damaging the NPT and DMJ. A Baltimore stereotaxic instrument was used, and the lesions were made by passing DC (2.0-2.5 ma. for NPT lesions, $1.8 \mathrm{ma}$. for DMJ lesions) for $10 \mathrm{sec}$. through an electrode with $1 \mathrm{~mm}$. of the tip uninsulated. After the completion of the postoperative test, each $\underline{S}$ was sacrificed with an overdose of Nembutal, the brain removed and allowed to harden for $48 \mathrm{hr}$. in a $10 \%$ formalin solution. Subsequent $1 \mathrm{y}$, the brain was sectioned frontally at $90 \mu$ with a freezing microtome. Every third section through the damaged area was photographed at $10 \mathrm{X}$ with the use of a Leitz enlarger.

An estimate of the extent and locus of lesions to the NPT was made by using a method similar to that described by McNew and Thompson (1966). Brain sections through the lesioned area were placed on slides 
and traced after enlargement onto worksheets derived from Gurdjian's (1927) description of the NPT. From these worksheets estimates were made of the percent damage to the NPT, structures dorsal to the NPT, and ventral areas. A check (test-retest) made to determine the reliability of the obtained rankings resulted in Spearman Rho coefficients (Siege1, 1956, p. 202) of .98, .99, and .98, respectively. Animals with at least $25 \%$ bilateral damage to the NPT were assigned to Group NPT.

Apparatus

The apparatus was a 2-choice discrimination chamber similar to the one described by Thompson and Bryant (1955). It consisted of three clearly defined compartments: a start box, a choice chamber, and a wooden-floored goal box. Both the start box and the choice chamber had grid floors through which an electric current could be passed. The exit from the choice chamber was through two windows (5 $1 / 2$ in. square) which led into the goal box. These windows were normally covered by the discrimination cards, one of which could not be pushed aside. A 3 in. section of the grid in front of each window could be charged independently from the rest of the grid floor. All parts of the grid floor were connected to a variable powerstat.

\section{Procedure}

Preliminary training. On the first day, each animal had its vibrissae shaved, its ears clipped for identification, and was placed in the goal box for approximately $15 \mathrm{~min}$. During this time, each $\underline{\mathrm{S}}$ 
was picked up by $\underline{E}$ and carried to the opposite end of the apparatus at least once. On the second day, each $\underline{S}$ was taught to push aside cards in order to gain access to the goal box. This training was accomplished in the following manner: $\underline{S}$ was placed in the start box and the plexiglas door separating the start box and choice chamber raised; $\underline{S}$ was given $5 \mathrm{sec}$. to enter the choice chamber after which entry was forced by mild foot-shock; once in the choice chamber, $\underline{S}$ was allowed approximately $30 \mathrm{sec}$. to enter the goal box before further foot-shocks were administered.

For the first three trials of preliminary training, the training cards (medium gray) positioned at each window only partially blocked the entrance to the goal box. As training proceeded, the cards were gradually placed in a flush position. Preliminary training was terminated when $\underline{S}$ readily pushed aside the card in order to gain access to the goal box. A $60 \mathrm{sec}$. intertrial interval was employed throughout preliminary training, discrimination training, and postoperative retraining.

\section{Discrimination training. Twenty-four hours after preliminary} training, each $\underline{S}$ was given 8 trials per day on the size discrimination problem. Pushing aside the unlocked large-disk card ( 4 in. diameter white disk centered on black backsround) was counted as a correct response, while receipt of foot-shock in front of the locked sma11disk card ( $7 / 8$ in. diameter white disk centered on black background) was scored as an error. The correction method was used throughout the study. Appearance of the positive card in the left or right window 
varied according to a strict double-alternation pattern except during overtraining at which time a combination of single-alternation and double-alternation was employed. The procedure adopted in preliminary training with respect to placing $\underline{S}$ in the start box, opening the entrance to the choice chamber, and forcing a choice of exits was continued throughout the preoperative and postoperative testing periods. The criterion of learning on the size discrimination problem was at least 15 out of 16 correct responses on 2 consecutive days. When this performance level was attained, each $\underline{S}$ received an additional 50 trials of overtraining at a rate of 10 trials per day for 5 successive days.

Following overtraining on the size discrimination problem, al1 Ss were required to lo arn a horizontal-vertical (1/2 in. striations for alternating black and white stripes) discrimination problem. The animals were trained to approach the card with horizontal stripes and to avoid the card with vertical stripes. Again the criterion for mastery was 15 out of 16 correct responses, and 50 overtraining trials were given.

Postoperative retention test. Surgery was carried out within two days following completion of discrimination training. Informal observational records were kept from the day after the operation until the day retention testing began. These records consisted of the following observations: weight data, quality and quantity of locomotor activity, use of vibrissae, excitability to handling and hand-claps, pupil size, and general physical appearance. 
Retention testing began approximately 28 days following the first operation (14 days after the second lesion in Group NPT-2) in Groups NPT-1, NPT-2, and $\mathrm{C}$ and from 14-21 days in Group DMJ. Each $\underline{\mathrm{S}}$ was required to relearn the two discrimination problems in the order in which they were originally mastered. The procedure employed in relearning was identical to that used in original learning.

A modification in the retention testing procedure was made for Ss that failed to reach the criterion after committing $21 / 2$ times the number of errors made in original learning. Training on the size discrimination was interrupted, and the animals were placed on a simple brightness discrimination (white card, positive; black card, negative). When a criterion of 14 correct in two days or 8 correct responses in one day had been reached, the black card was replaced by the sma11-disk card and the animals trained to the less stringent criterion. Training on the original size discrimination was reinstated after the white card vs. small-disk card problem had been mastered.

Animals exhibiting difficulty relearning the pattern discrimination problem were terminater on the task after making $21 / 2$ times the errors made in original learning. Training on the size discrimination to a criterion of 7 correct in 8 trials was given prior to testing on the size threshold task.

Size threshold test. Following relearning (but not overtraining) of the horizontal-vertical discrimination, the majority of $\underline{s}$ were tested on a size discrimination threshold task. This task consisted of the positive $4 \mathrm{in}$. disk card paired successively with 
negative stimulus cards having disk-diameters of 1 in., 2 in., 2 1/2 in., and 3 in. The criterion for successful completion of each task was designated as 7 correct responses in 8 trials. Testing was terminated when $\underline{S}$ completed the four threshold discriminations or when 15 errors were made on any problem.

Statistica1 analyses. Percentage of error savings was the measure of retention. The savings score was based on errors made by an animal prior to achieving a significant run of perfect (Grant, 1947) or near-perfect (Runnels, Thompson, and Runnels, 1968) trials. This "significant run" savings score was used in addition to the traditional "errors-to-criterion" savings score.

The majority of the statistical analyses were computed for both the "significant run" savings score (SRSS) and the "criterion run" savings score (CRSS), and the .05 level of significance (one-tail) was accepted for al1 tests. In order to evaluate individual retention scores, a loss of retention was defined as a savings score (SRSS, CRSS)

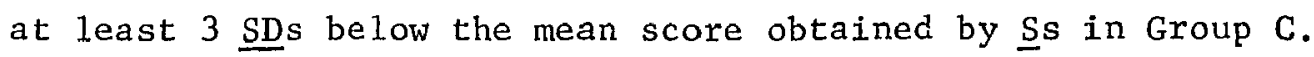

In order to statistically evaluate performance on the size discrimination threshold series, each $\underline{S}$ received a rank based on both the number of tasks completed and the total number of errors made on the series. Thus the animal completing the fewest tasks received the primary rank. Subjects completing the same number of tasks were further ranked according to total errors with the lowest rank accorded the animal committing the most errors. 
RESULTS

\section{Preoperative Performance}

The size discrimination problem used in the current study was considerably more difficult to learn than was the pattern discrimination problem. A nonparametric test (Mann and Whitney, 1947) comparing the number of errors made on each problem prior to the criterion run resulted in a significant difference. However, there was no difference between the two problems in terms of percentage of correct responses made during overtraining (mean performance $95.2 \%$ for both problems).

In order to determine whether or not the four groups of animals (Groups $\mathrm{C}, \mathrm{NPT}-1, \mathrm{NPT}-2, \mathrm{DMJ}$ ) differed with respect to original learning ability, nonparametric analyses of variance (Kruskal and Wallis, 1952) comparing errors to criterion for each problem were computed. The obtained H's were not significant. Preoperative learning performance for each group is summarized in Table 1 . 
TABLE 1

PREOPERATIVE LEARNING PERFORMANCE OF GROUPS C, NPT-1, NPT-2, DMJ

\begin{tabular}{|c|c|c|c|c|c|c|c|}
\hline \multirow[b]{2}{*}{ Group } & \multirow[b]{2}{*}{$\mathrm{N}$} & \multicolumn{3}{|c|}{ Size Discrimination } & \multicolumn{3}{|c|}{ Form Discrimination } \\
\hline & & $\begin{array}{l}\text { Mean errors } \\
\text { to SR }\end{array}$ & $\begin{array}{c}\text { Mean errors } \\
\text { to } \mathrm{CR}\end{array}$ & $\begin{array}{l}\% \text { correct in } \\
\text { overtraining }\end{array}$ & $\begin{array}{c}\text { Mean errors } \\
\text { to } S R\end{array}$ & $\begin{array}{c}\text { Mean errors } \\
\text { to } \mathrm{CR}\end{array}$ & $\begin{array}{l}\% \text { correct in } \\
\text { overtraining }\end{array}$ \\
\hline $\mathrm{C}$ & 7 & 23.6 & 30.1 & 97.1 & 12.3 & 14.1 & 93.7 \\
\hline NPT -1 & 10 & 19.5 & 21.9 & 95.0 & 12.0 & 16.3 & 95.2 \\
\hline NPT -2 & 10 & 18.0 & 20.5 & 96.6 & 15.2 & 16.8 & 96.2 \\
\hline DMJ & 7 & 24.1 & 27.4 & 92.0 & 15.6 & 19.3 & 95.7 \\
\hline
\end{tabular}




\section{Postoperative Performance}

Retention of Size and Pattern Problems

1-stage vs. 2-stage NPT 1esions. A nonparametric analysis of variance test $(\mathrm{K}-\mathrm{W})$ comparing the retention scores of Groups $\mathrm{C}$, NPT-1, NPT-2, and DMJ resulted in significant $H^{\prime} s$ for retention of the size discrimination (SRSS, CRSS) and for retention of the form discrimination (CRSS). Since the $\mathrm{K}-\mathrm{W}$ test comparing the four groups on SRSS retention of the form discrimination resulted in an $\mathrm{H}$ approaching statistical significance $(\mathrm{H}=7.5, \mathrm{p}<.10)$, U tests were computed for al1 possible comparisons and are summarized in Table 2.

With respect to retention of the size discrimination, both NPT groups performed significantly poorer than Group C. In addition, Group NPT-2 was significantly worse than Group $\mathrm{C}$ with respect to retention of the form discrimination. No significant differences were found when retention scores were compared for Groups NPT-1 and NPT-2. Figure 1 shows the lesions of two NPT $\underline{S}$ s having retention deficits on both problems.

An uncomplicated comparison of the performance of NPT-1 and NPT-2 Ss would obviously require that each group have approximately equal amounts of damage to the NPT. In order to meet this requirement, two Ss were discarded from each group leaving 8 matched pairs (mean percent damage to the NPT $51.8 \%$ and $53.3 \%$, respective1y). Figure 2 shows the lesions of two $\underline{\text { S }}$ (left column, Group NPT-1; right column, Group NPT-2) matched in terms of the amount of damage to the NPT. 
TABLE 2

MEAN RETENTION SCORES FOR GROUPS C, NPT-1, NPT-2, DMJ

\begin{tabular}{|c|c|c|c|c|c|c|c|c|c|}
\hline \multirow[b]{2}{*}{ sroup } & \multirow[b]{2}{*}{$\mathrm{N}$} & \multicolumn{4}{|c|}{ Size Discrimination } & \multicolumn{4}{|c|}{ Form Discrimination } \\
\hline & & $\begin{array}{l}\text { Mean \% } \\
\text { SRSS }\end{array}$ & Range & $\begin{array}{l}\text { Mean \% } \\
\text { CRSS }\end{array}$ & Range & $\begin{array}{l}\text { Mean } \% \\
\text { SRSS }\end{array}$ & Range & $\begin{array}{c}\text { Mean } \% \\
\text { CRSS }\end{array}$ & Range \\
\hline C & 7 & 97.4 & $91-100$ & 96.9 & $87-100$ & 99.3 & $95-100$ & 98.6 & $90-100$ \\
\hline $\mathrm{NPT}-1$ & 10 & $65.5^{a}$ & $-33-100$ & $50.9^{a}$ & $-130-100$ & 89.9 & $9-100$ & 80.6 & $8-100$ \\
\hline NPT -2 & 10 & $55.4^{a}$ & $-94-100$ & $33.1^{\mathrm{a}}$ & $-130-100$ & $78.3^{a}$ & $-36-100$ & $58.2^{a}$ & $-38-100$ \\
\hline pMJ & 7 & $41.1^{a}$ & $-31-94$ & $-7.0^{\mathrm{a}, \mathrm{b}}$ & $-248-89$ & $85.9^{a}$ & $50-100$ & $17.0^{a, b}$ & $-150^{+}-95$ \\
\hline
\end{tabular}

$a_{\text {Significant group differences: }}$ NPT-1>C, NPT-2>C, DMJ $>$ C.

${ }^{\mathrm{b}}$ Significant group differences: $\mathrm{DMJ}>\mathrm{NPT}-1$. 


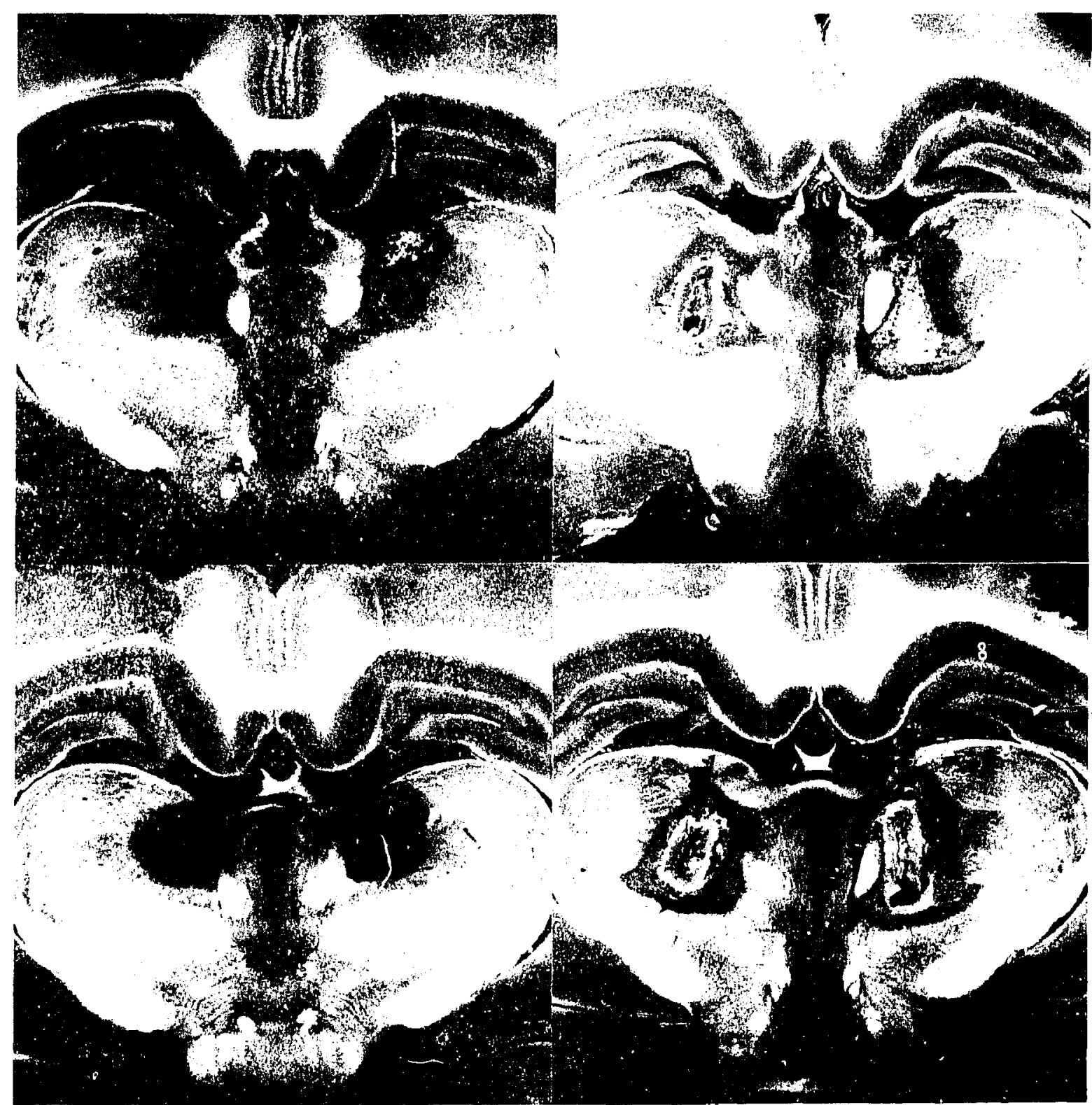

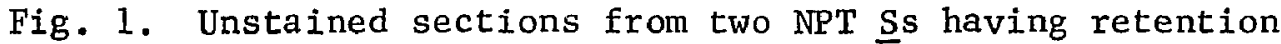
loss on both problems. (Left column--NPT-1-56, $43 \%$ bilateral NPT damage: size discrimination $=41 \%, 21 \%$; form discrimination $=90 \%$, $86 \%$. Right column --NPT-2-19, 32\% bilateral NPT damage: size discrimination $=52 \%, 66 \%$; form discrimination $=-36 \%,-25 \%$.) 


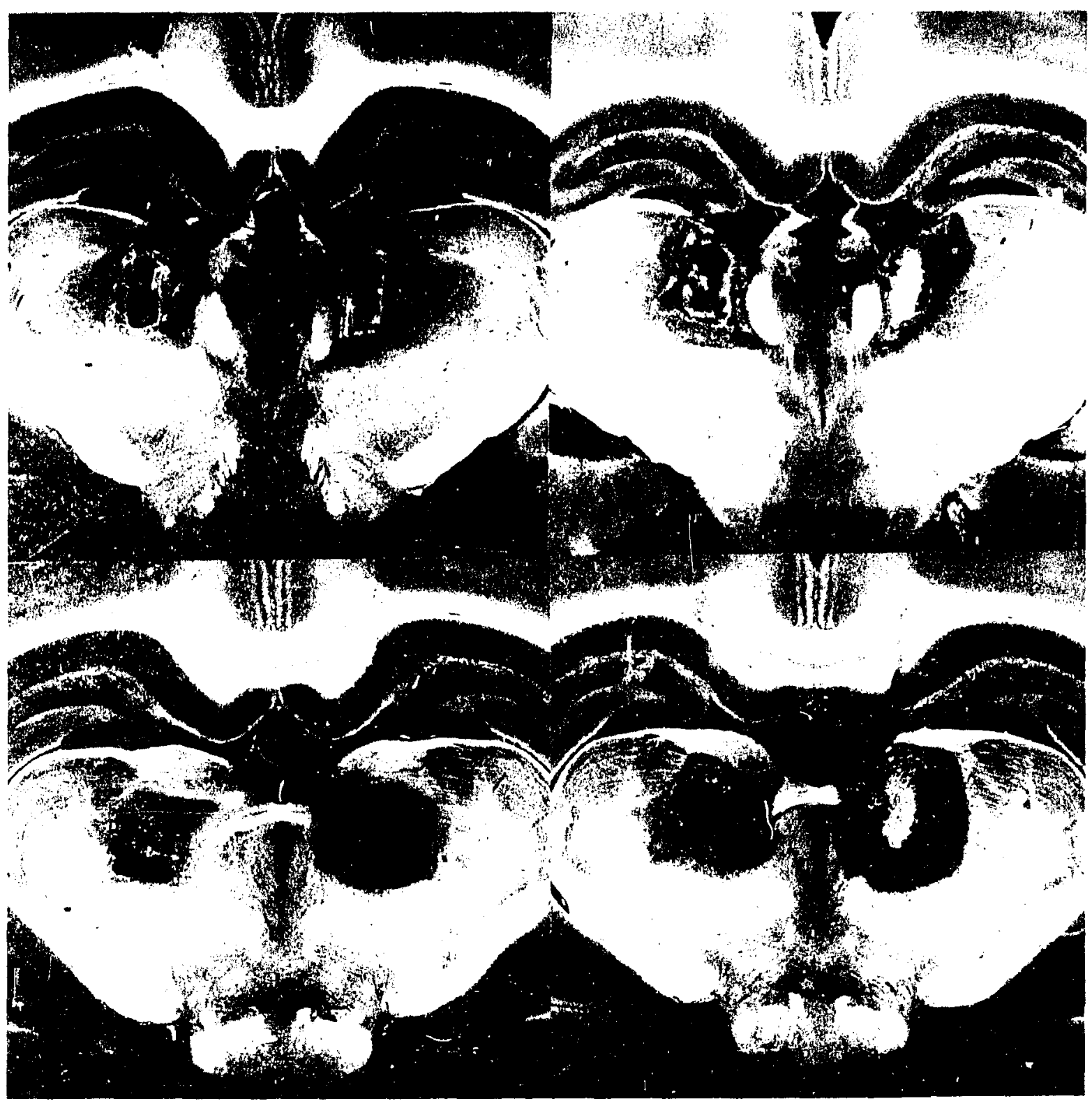

Fig. 2. Unstained sections from two Ss having approximately equivalent damage to NPT. (Left column--NPT-1-45, $61 \%$ bilatera1 damage to NPT: size discrimination $=100 \%$, $93 \%$; form discrimination = $100 \%, 100 \%$. Right column - -NPT-2-44, 64\% bilateral damage to NPT: size discrimination $=100 \%, 100 \%$; form discrimination $=100 \%$, $100 \%$ ) 
Mean retention scores for the two groups were as follows: Group NPT-1 size discrimination $=67.3,49.9$, pattern discrimination $=87.4,83.3$; Group NPT-2 size discrimination $=70.1$, 46.9, pattern discrimination $=$ 73.9, 51.4. A nonparametric test comparing two related samples (Wilcoxon, 1945) was used to determine the significance of differences in retention of the size and form discrimination problems. The T's were not significant at the .05 level although differences between the groups with respect to retention of the pattern discrimination approached statistical significance.

DMJ 1esions. Retention of both the size and the form discrimination problems was significantly poorer for Group DMJ than for Group C. No differences in retention were found between Groups DMJ and NPT-2. Group DMJ did not differ significantly from Group NPT-1 with respect to the SRSS measure but had significantly more difficulty attaining the criterion of learning on both problems. Comparisons for Group DMJ are summarized in Table 2 .

\section{Overtraining Accuracy}

The mean overtraining scores for Groups $\mathrm{C}, \mathrm{NPT}-1, \mathrm{NPT}-2$, and DMJ were 97.4, 95.4, 91.6, and 93.1, respectively. On1y Group NPT-2 was found to differ significantly from Group $\mathrm{C}$ when nonparametric comparisons were made. For Group NPT-2, overtraining performance was not highly correlated with an overal1 measure of retention (Rho=.04). Size discrimination threshold performance The $\mathrm{K}-\mathrm{W}$ test comparing performance on the threshold task for 
the four groups did not result in a significant difference. Table 3 summarizes performance by the four groups on the threshold task.

TABLE 3

NUMBER OF SS IN EACH GROUP ATTAINING CRITERION ON SIZE DISCRTMINATION THRESHOLD TASKS

\begin{tabular}{c|c|c|c|c|c|c|c}
\hline \hline Group & N & \multicolumn{2}{|c|}{ Circle diameters of negative stimu1us cards } & Mean rank \\
& & $13 / 4$ in. & 2 in. & 2 l/2 in. & 3 in. & \\
\hline C & 6 & 6 & 6 & 6 & 5 & 17.9 \\
NPT-1 & 7 & 7 & 7 & 6 & 3 & 10.1 \\
NPT-2 & 6 & 6 & 6 & 6 & 5 & 15.0 \\
DMJ & 7 & 6 & 6 & 5 & 4 & 11.9 \\
\hline
\end{tabular}

In order to determine the extent to which postoperative performance on the discrimination problems was correlated with size threshold ability, Spearman Rho correlation coefficients were computed (Table 4). None were significant.

TABLE 4

SPEARMAN RHO CORREIATION COEFFICIENTS BETWEEN RETENTION SCORES AND SIZE THRESHOLD PERFORMANCE COMPUTED ON THE OPERATE $\underline{S}$

\begin{tabular}{|c|c|c|c|c|c|}
\hline \multicolumn{2}{|l|}{ Mea sure } & \multicolumn{2}{|c|}{$\begin{array}{l}\text { Size discrimination } \\
\text { retention }\end{array}$} & \multicolumn{2}{|c|}{$\begin{array}{c}\text { Form discrimination } \\
\text { retention }\end{array}$} \\
\hline & & SRSS & CRSS & SRSS & GRSS \\
\hline \multirow{3}{*}{$\begin{array}{l}\text { Size threshold } \\
\text { discrimination }\end{array}$} & $\mathrm{NPT}-1$ & .14 & .12 & .36 & .29 \\
\hline & & .37 & .26 & .53 & .43 \\
\hline & DMJ & -.36 & .22 & .37 & .07 \\
\hline
\end{tabular}


Lesion locus and performance

Spearman Rho correlations between amount of damage to a given area of the posterior thalamus and retention of the discrimination problems were computed on the combined NPT groups in order to determine a critical area for retention loss. All correlations between both the NPT and the area immediately dorsal to it (pretectal nucleus, lateral posterior thalamic nucleus) and retention were found to be negative. On the other hand, damage to an area including the ventral portion of the NPT and the medial portion of the nucleus ventralis was found to be positively and significantly (size discrimination, SRSS; form discrimination, CRSS) correlated with retention. Table 5 summarizes the correlations computed.

TABLE 5

SPEARMAN RHO CORRELATION COEFFICIENTS BETWEEN RETENTION SCORES AND \% DAMAGE TO THALAMIC AREAS FOR SSs IN COMBINED NPT GROUPS

\begin{tabular}{l|c|c|c|c}
\hline & \multicolumn{2}{|c|}{$\begin{array}{c}\text { Size discrimination } \\
\text { retention }\end{array}$} & \multicolumn{2}{|c}{$\begin{array}{c}\text { Form discrimination } \\
\text { retention }\end{array}$} \\
Lesioned area & SRSS & CRSS & SRSS & CRSS \\
\hline NPT & $-.44 *$ & $-.42 *$ & -.28 & -.31 \\
Dorsa1 to NPT & $-.41 *$ & -.23 & -.35 & $-.49 *$ \\
Ventra1 to NPT & $.46 *$ & .34 & .26 & $.44 *$ \\
\hline
\end{tabular}

* Significant at .05 leve 1 
Figure 3 depicts five sections through the rat brain beginning with a section through the anterior portion of the NPT and ending with a section showing the rostral portion of the red nucleus. On the right half of each section, the path taken by descending fibers from the NPT [adapted from Knook (1966, p. 331), Krieg (1947), and Papez and Freeman (1930)] is shown. This pathway descends through the posterior thalamus and DMJ, maintaining a position immediately dorsal to the medial lemniscus and lateral to the fasciculus retroflexus, and disappears at the level of the red nucleus. A composite drawing of lesions producing losses on both problems is shown for comparison on the left side of Figure 3.

of the 7 Ss receiving bilateral damage to the DMJ, 4 displayed loss of retention for both retention measures on both problems. In addition, one other $\underline{S}$ exhibited loss of retention of the size discrimination problem and had difficulty reaching criterion on the form discrimination task. The only $\underline{S}(D M J-70)$ having normal retention of both problems received a dorsal DMJ lesion destroying much of the pretectal area and the medial part of the superior colliculus. The lesion of DMJ-70 and the lesion of a $\underline{S}$ exhibiting a loss of retention of both problems are illustrated in Figure 4 .

Other behavioral observations

A11 operated animals, with the exception of NPT-2 $\underline{s}$, exhibited aphagia and adipsia for several days postoperatively. Soft, palatable food (a mixture of ground rat pellets, sugar, powdered milk, and water) 


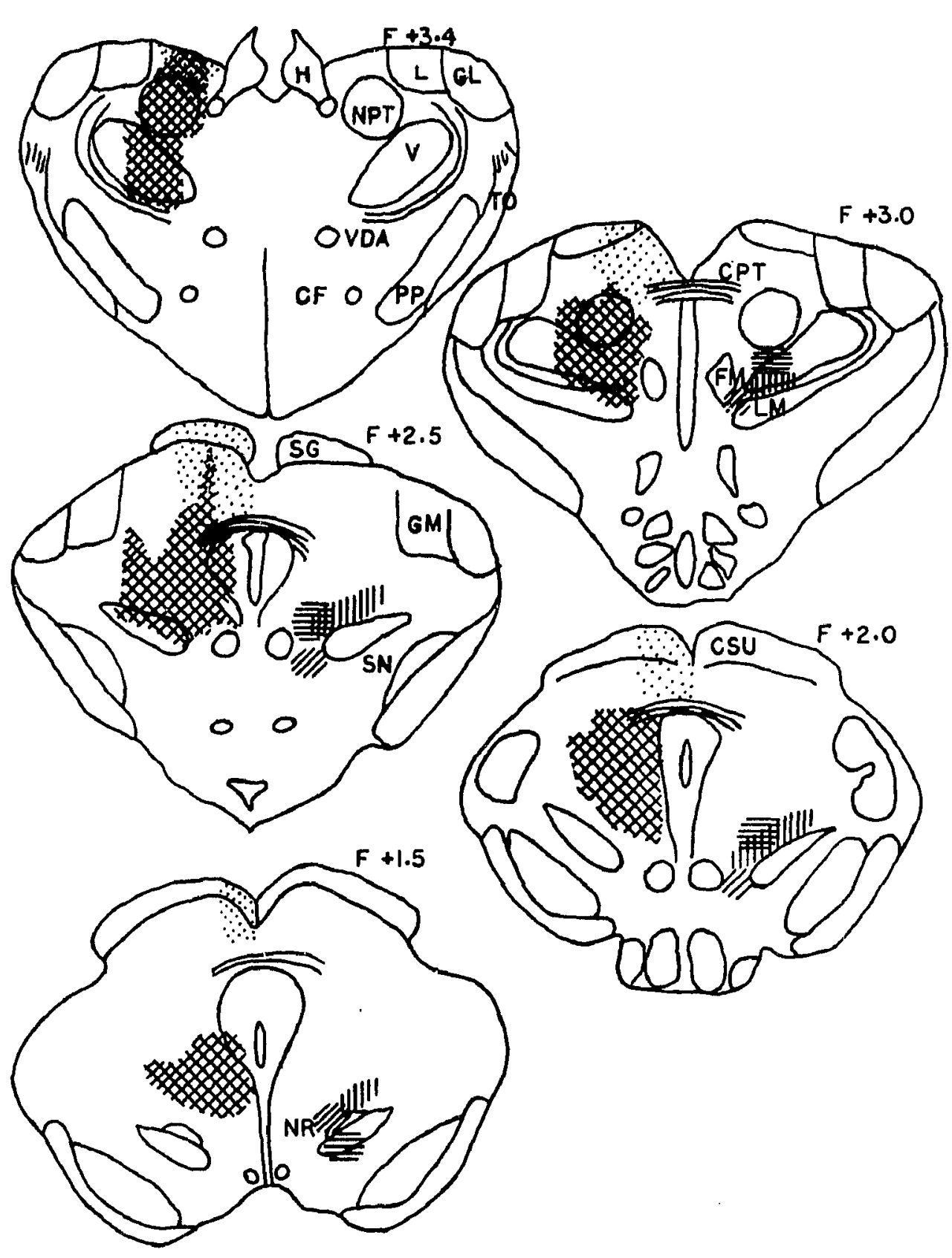

Fig. 3. Five frontal levels derived from the Massopust (1961) atlas. (Right half of each section--pathways from NPT to RN adapted from Knook, vertical lines; Krieg, horizontal lines; and Papez \& Freeman, diagonal lines. Left half of each section--composite damage to Ss having loss on both problems, crosshatched; $\underline{S}$ with normal retention of both problems, stippled. Abbreviations: $\mathrm{CF}=$ fornix column, CPT=posterior commisure, CSU=superior colliculus, FM=fasciculus retroflexus, $G L=1 a t e r a l$ geniculate nucleus, $G M=$ medial geniculate nucleus, $H=H a b e n u l a, L=1$ ateral thalamic nucleus, LM=medial lemniscus, $\mathrm{NPT}=$ nucleus posterior thalami, $\mathrm{NR}=\mathrm{red}$ nucleus, $\mathrm{PP}=$ cerebral peduncle, $\mathrm{SG}=$ stratum griseum, $\mathrm{SN}=$ substantia nigra, $\mathrm{TO}=$ optic tract, V=ventral thalamic nucleus, VDA=mammillothalamic tract.) 


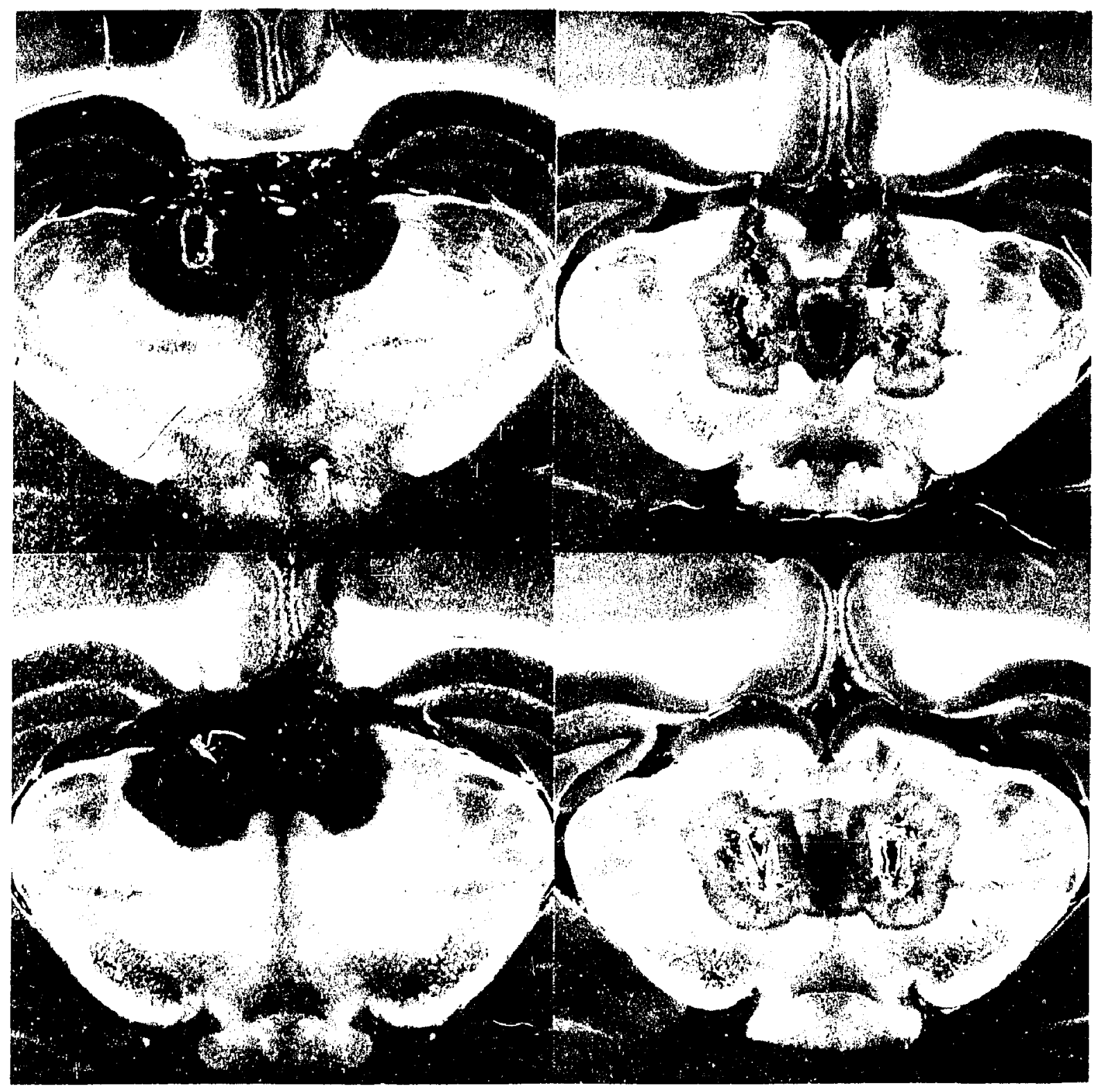

Fig. 4. Unstained sections from two DMJ Ss. (Left column-DMJ-70, size discrimination $=92 \%, 89 \%$; form discrimination $=$ $97 \%$, 95\%. Right column--DMJ-62, size discrimination $=-31 \%,-35 \%$; form discrimination $=93 \%, 67 \%$.) 
placed in the cage with the Ss usually induced feeding within the first postoperative week.

Several transient deficits were seen in all operated groups. The main ones were loss of vibrissae movement (either unilaterally or bilatera1ly), dilated pupils, circling, and head canting. In almost al1 cases, these defects were temporary and had disappeared by the time retention testing began.

During retention testing, almost all lesioned animals were indistinguishable from the normal controls in terms of orientation to stimulus cards, number of foot-shocks required to induce running, and emotional behavior in the apparatus. Almost all ss with lesions in the DMJ area exhibited, at least temporarily, difficulty pushing open the positive stimulus card. In addition, DMJ-40 explored the choice chamber on almost every trial during retention testing despite repeated shocks for such behavior. The exploratory tendency of this $\underline{S}$ probably accounted for the difficulties it had in attaining the criterion of 15 correct responses in 16 trials. 


\section{DISCUSSION}

The results of the present study support previous work (e.g.,

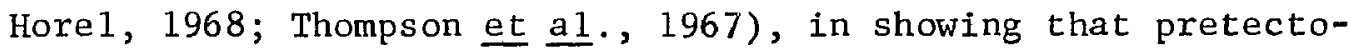
diencephalic lesions significantly impair retention on visual discrimination problems. However, the observed deficits were neither striking nor positively correlated with the extent of damage to the NPT, a finding which is at variance with earlier reports (Breen, 1965; McNew and Thompson, 1966; Thompson and Rich, 1961; Thompson, et a1., 1967). Instead, in partial agreement with Breen and McNew and Thompson, the amount of damage to the region immediately ventral to the NPT (medial part of the nucleus ventralis) was found to be significantly correlated with the magnitude of the retention deficit. Differences in experimental procedures between the present study and previous experiments may, in part, account for the failuie of this experiment to obtain positive correlations between extent of damage to the NPT and retention deficits. One difference stems from the fact that $\underline{S} s$ in previous studies did not receive overtraining on the visual discrimination problems prior to brain damage. In a study comparing overtrained and criterion trained $\underline{S}$ s, Lukaszewska and Thompson (1967) found that overtrained NPT animals exhibited significantly better retention of a pattern discrimination problem than criterion trained $\underline{\text { S }}$. Lukaszewska and Thompson concluded that overtraining on the pattern discrimination enables the problem to take on features of a simpler 
problem and thus makes it more resistant to disruption by brain damage. In addition, probably because of the difficulty of the size discrimination problem used in the present study, Ss exhibited positive transfer upon initial exposure to the form discrimination and learned the latter problem much more rapidly than the former. Lack of a significant difference between Group NPT-1 and Group C with respect to SRSS retention of the pattern discrimination was possibly the result of the combination of overtraining and difficult size discrimination.

Another difference between the present study and previous studies can be traced to the fact that relatively smal1 lesions were made in the current experiment. For example, the mean percent damage to the NPT in the present study was $53.3 \%$ as compared to a mean of $69.6 \%$ in Experiment 1 of the Thompson et a1. (1967) report. The combination of overtraining and relatively small lesions may have militated against positive correlations by producing both a larger critical area within the pretectum and relatively minor amounts of damage to this critical area, respectively. The one locus of damage found to be positively correlated with loss of retention was in an area immediately ventral to the NPT. Inspection of Figure 3 reveals that this area is traversed by the descending pathway connecting the NPT with the red nucleus. In addition, Faul1 and Carman (1968) reported that prerubral radiations ascend to the medial portion of the ventral thalamic nucleus. The fact that Groups NPT-1 and NPT-2 were comparable in retention fails to provide evidence in support of a diaschisis explanation for retention deficits following NPT lesions. With the exception of 
more rapid recovery following 2 -stage lesions (this was not reflected in differential mortality rates), there was little to distinguish 2 -stage and 1-stage lesioned animals in the present study. This finding contrasts with those reported by Adametz (1959), Ades and Raab (1949), and Stewart and Ades (1951).

Although significant losses in retention were seen between each operated group and the controls, performance by the brain-damaged animals on the size discrimination threshold task was not significantly poorer than that of normal $\underline{S}$ s. Since several brain-damaged $\underline{S}$ exhibited excellent retention of one or both discrimination tasks, a check was made to determine the extent to which performance on the discrimination tasks was correlated with threshold task performance. The results of the obtained correlations revealed that poor discrimination performance was not significantly correlated with inability to master the threshold tasks. Therefore, from the results of the present experiment, it may be concluded that loss of visual discrimination retention following damage to the posterior thalamus and/or the pathway connecting the NPT and the red nucleus is not primarily a function of loss of visual acuity.

The present study also provided evidence supporting the results of a previous study by Thompson et al. (1964) who found that knife cuts separating the posterior thalamus and red nucleus produced retention deficits for a brightness discrimination. Lesions in the DMJ region of the brainstem closely corresponding to the trajectory of the NPT efferent tract described by Knook (1966, p. 331), Krieg (1947), and 
Papez and Freeman (1930), produced significant losses of retention on both problems.

Another possible explanation for retention losses following NPT damage is that of a defect in attention (Thompson et al., 1967). Animals with NPT lesions in the current study exhibited at least three defects which might lend support to an attentional loss hypothesis. First of a11, NPT Ss (excluding animals with perfect retention) had difficulty attaining the high degree of performance necessary for the criterion run. This difficulty was reflected in a significant difference between errors to $S R$ and errors to CR. Secondly, postoperative performance on overtraining was poorer for NPT-2 $\underline{S}$ s than for controls. Thirdly, a few $\underline{S} s$ with poor savings scores displayed a tendency to explore the choice chamber. However, an attentional defect is probably not sufficient to explain performance deficits following NPT lesions since several $\underline{\text { S }}$ performed poorly on the discrimination problems without exhibiting any of the above defects. Additionally, overtraining performance for Group NPT-2 was not highly correlated with retention performance.

It is highly probable that a unitary explanation for visual discrimination deficits following posterior thalamic lesions does not exist. Instead, some combination of mild attentional loss, loss of visual acuity, and increase in threshold for pain [Thompson et al. (1967) found that NPT Ss had difficulty making a correction response after an error was committed] might provide a more satisfactory explanation. 


\section{SUMMARY}

Two possible explanations for amnestic effects following lesions in the posterior thalamus are diaschisis and loss of visual acuity. In addition to obtaining data relevant to the two explanations for NPT deficits, the present experiment examined the functional significance of an efferent pathway through the di-mesencephalic juncture (DMJ) connecting the NPT and the red nucleus. Al1 Ss were trained and overtrained on a size discrimination problem and a pattern discrimination task, and most animals were tested on a size discrimination threshold task after retention testing.

To test for diaschitic effects, sever.. animals were subjected to either 1-stage or 2-stage NPT lesions. After recovery, brain-

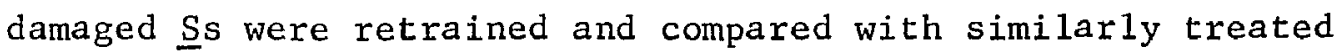
unoperated controls for retention of the problems. Group NPT-I was significantly poorer than Group $\mathrm{C}$ with respect to retention of the size discrimination, and Group NPT-2 performed worse than the controls on both discrimination problems. Groups NPT-1 and NPT-2 did not differ significantly. The threshold task, a test of visual acuity, did not differentiate brain-damaged and control Ss.

Animals with DMJ lesions were found to be significantly poorer than normals with respect to retention of both visual discrimination problems. Performance on the size threshold task was not significantly different for DMJ lesioned $\underline{S}$ s and controls. 
It was concluded that neither diaschisis nor loss of visual acuity can adequately account for retention deficits after NPT lesions. The brainstem area through which an efferent fiber tract connecting the NPT and red nucleus passes was found to be critical for normal retention of visual discrimination problems. 


\section{REFERENCES}

Adametz, J. H. Rate of recovery of functioning in cats with rostral reticular lesions. Journal of Neurosurgery, 1959, 16, 85-97.

Ades, H. W., and Raab, D. H. Effects of preoccipital and temporal decortication on learned visual discrimination in monkeys. Journal of Neurophysiology, 1949, 12, 101-108.

Breen, T. E. The effect of occipital and pretectal lesions on retention of easy and difficult brightness discriminations in the rat. Unpublished doctoral dissertation, L.S.U., 1965.

Faul1, R. L. M., and Carman, J. B. Ascending projections of the substantia nigra in the rat. Journal of Comparative Neurology, 1968, 132, 73-92.

Ghise11i, E. E., and Brown, C. W. Subcortical mechanisms in learning. III. Brightness discrimination. Journal of Comparative Psychology, 1938, 26, 93-107.

Goodman, D. C., and Hore1, J. A. Sprouting of optic tract projections in the brain stem of the rat. Journal of Comparative Neurology, 1966, 127, 71-88.

Grant, D. A. Additional tables of the probability of "runs" of correct responses in learning and problem solving. Psychological Bulletin, 1947, 44, 558-561.

Gurdjian, E. S. The diencephalon of the albino rat: Studies on the brain of the rat. Journal of Comparative Neurology, 1927, $43,1-114$.

Hore1, J.A. Effects of subcortical lesions on brightness discrimination acquired by rats without visual cortex. Journal of Comparative and Physiologica1 Psychology, 1968, 65, 103-109.

Knook, H. L. The fibre-connections of the forebrain. Philadelphia: F. A. Davis, 1966 .

Krieg, W. J. S. Connections of the cerebral cortex. 1. The albino rat. C. Extrinsic connections. Journal of Comparative Neurology, 1947, 86, 267-394. 
Kruska1, W. H., and Wallis, W. A. Use of ranks in one-criterion variance analysis, Journal of the American Statistical Association, $1952, \underline{47}, 583-6 \overline{21}$.

Lashley, K. S. The mechanism of vision. XII. Nervous structures concerned in the acquisition and retention of habits based on reactions to light. Comparative Psychological Monographs, $1935,11,43-79$.

Layman, J. D. Functions of the superior colliculus in vision. Journal of Genetic Psychology, 1936, 49, 33-47.

Lukaszewska, I., and Thompson, R. Retention of an overtrained pattern discrimination following pretectal lesions in rats. Psychonomic Science, 1967, $\underline{8}, 121-122$.

McNew, B. R., and Thompson, R. Effect of posterior thalamic lesions on retention of a brightness discrimination motivated by thirst. Journal of Comparative and Physiological psychology, $1966, \underline{62}, 125-128$.

Mann, H. B., and Whitney, D. R. On a test of whether one of two random variables is stochastically larger than the other. The Anna 1s of Mathematica1 Statistics, 1947, 18, 50-60.

Massopust, L. C. A stereotaxic atlas of the diencephalon of the rat. In D. E. Sheer (Ed.), Electrical stimulation of the brain. Austin, Texas: University of Texas Press, 1961.

Papez, J. W., and Freeman, G. L. Superior colliculi and their fiber connections in the rat. Journal of Comparative Neurology, $1930,51,409-440$.

Runne1s, L. K., Thompson, R., and Runne1s, P. Near-perfect runs as a learning criterion. Journal of Mathematical Psychology, 1968, $\underline{5}, 362-368$.

Siege1, S. Nonparametric statistics for the behavioral sciences. New York: McGraw-Hi11, 1956.

Steward, J. W., and Ades, H. W. The time factor in reintegration of a learned habit lost after temporal lobe lesions in the monkey (Macaca mulatta). Journal of Comparativ $\geqq$ and Physiological Psychology, 1951, 44, 479-486.

Thompson, R. Thalamic structures critical for retention of an avoidance conditioned response in rats. Journal of Comparative and Physiologica 1 Psychology, 1963, 6, 261-267. 
Thompson, R. Centrencephalic theory and interhemispheric transfer of visual habits. Psychological Review, 1965, 72, 385-398.

Thompson, R., and Bryant, J. H. Memory as affected by activity of the relevant receptor. Psychologica1 Reports, 1955, 1, 393-400.

Thompson, R., Lesse, H., and Rich, I. Dissociation of visual and auditory habits following pretectal lesions in rats and cats. Journa1 of Comparative Neurology, 1963, 121, 161-172.

Thompson, R., Lukaszewska, I., Schweigerdt, A., and McNew, J. J . Retention of visual and kinesthetic discriminations in rats following pretecto-diencephalic and ventral mesencephalic damage. Journal of Comparative and Physiological Psychology, $1967, \underline{63}, 458-468$.

Thompson, R., and Massopust, L. C. Jr. The effect of subcortical lesions on retention of a brightness discrimination in rats. Journal of Comparative and Physiological Psychology, 1960, 53, $488-496$.

Thompson, R., and Rich, I. A discrete diencephalic pretecta1 area critical for retention of visual habits in the rat. Experimenta1 Neurology, 1961, 4, 436-443.

Thompson, R., and Rich, I. Differential effects of posterior thalamic lesions on retention of various visual habits. Journal of Comparative and Physiological Psychology, 1963, 6ㅡ, 60-65.

Thompson, R., Rich, I., and Langer, S. K. Lesion studies on the functional significance of the posterior thalamo-mesencephalic tract. Journa1 of Comparative Neurology, 1964, 123, 29-44.

Wilcoxon, $F$. Individual comparisons by ranking methods. Biometrics Bulletin, $1945, \underline{1}, 80-83$. 
VITA

Billy Michael Thorne was born September 7, 1942, in Shreveport, Louisiana. He received a Bachelor of Arts degree in sociology in January, 1964, from Louisiana State University. In February, 1964, he married the former Miss Wanda Bourgeois. In September, 1965, he entered graduate school at Louisiana State University from which he received his Master of Arts degree in psychology in May, 1967. From June, 1966, unti1 May, 1967, the author worked for Dr. Bil1y M. Seay as a research assistant in the Louisiana State University Primate Laboratory. He has held a National Aeronautics and Space Administration Traineeship from September, 1967, until the present. He has worked for Dr. Robert Thompson in the Louisiana State University Brain Research Laboratory since June, 1967. During the academic year 1968-69, he served as a Psychology Department teaching assistant. 
EXAMINATION AND THESIS REPORT

Candidate: Billy Michael Thorn

Major Field: $\quad$ Psychology

Title of Thesis: Visual Discrimination Performance in Rats Following Nucleus Posterior Thalami and Di-Mesencephalic Juncture Damage

Approved:

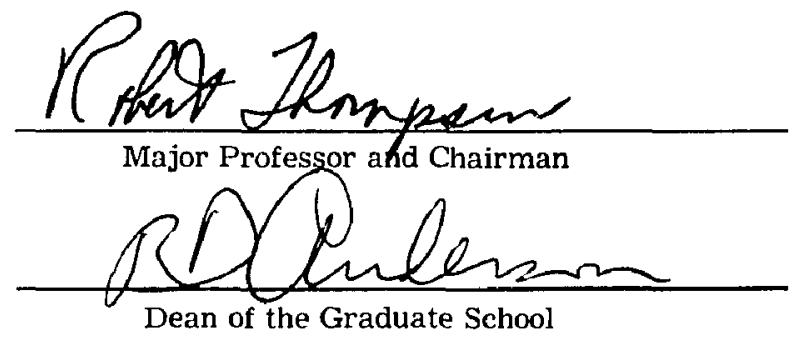

EXAMINING COMMITTEE:

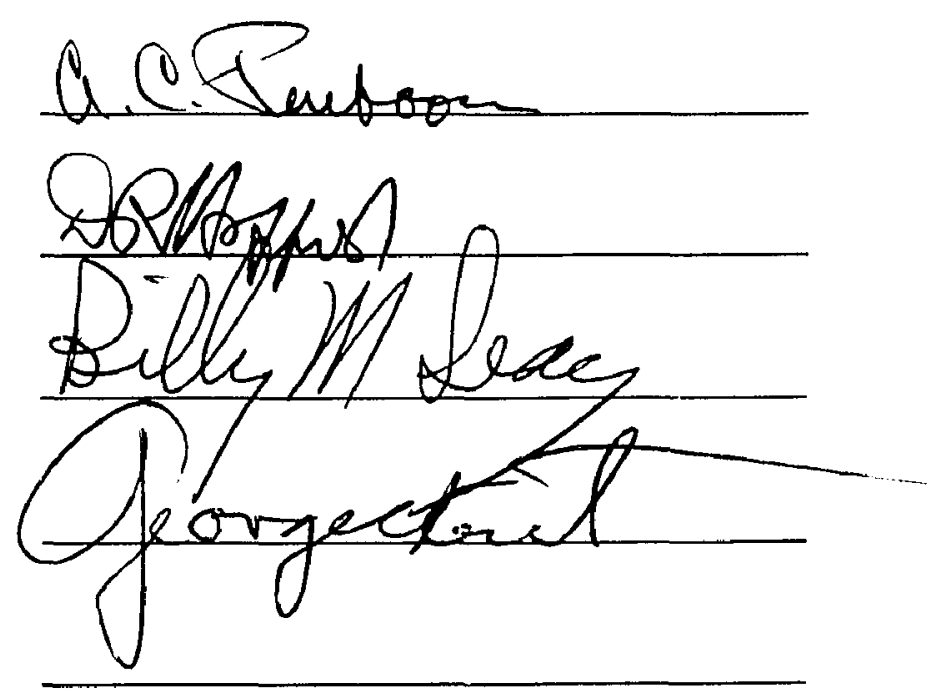

Date of Examination:

16 June 1969 